\title{
EUROPEAN TRENDS IN SOCIAL SERVICES' SYSTEMS: towards Marketization, User-involvement and Professionalization
}

\begin{abstract}
Social services systems in developed European states have undergone an intensive development due to increased demand for this type of services that are no longer designed to respond to the needs of only socially vulnerable and marginalized categories of users. This paper will make an overview of the key trends in these states that take place in this sector. In the core of this development process are the trends of mixed economy of welfare, i.e. welfare pluralism, as well as marketization of services and introduction of user participation to cover the costs of services. As a result, responsibilities and tasks are increasingly delegated to other sectors, in addition to the public sector that undertakes the role of service purchaser, and there is an increase in the profit-oriented service providers. Specific accent is put on the rights of users to be involved in the choice of services as well as on the support to families-caregivers through the social services system. Last but not least, the development of social services is accompanied by their professionalization through licensing of service providers (institutions and professionals) and enhancing criteria regarding qualifications of the work force engaged in the care services sector.
\end{abstract}

Keywords: SOCIAL SERVICES, PLURALISM, MARKETIZATION, USER-INVOLVEMENT, PROFESSIONALIZATION, LICENSING

\section{Introduction}

Dropping fertility rates, population ageing in most European countries, entry into the labour market of the traditional family carers - women, who usually look after dependent family members, as well as changes in the traditional family model towards increased number of single-parent families, divorces and re-marriages, are the key demographic trends that substantially affect the development path of social services in developed European countries (Munday, 2003). Moreover, an emphasis on active rather than passive measures, increased labour-force participation of women and calls for gender equality, have increased the need for service provision and have resulted in more rather than less investment in services in a large majority of the West European countries (Kautto, 2002). 
Under the influence of the above trends, social services sectors experience an intensive growth, while current analyses, debates and reform processes associated with social services in developed European countries are concentrated on several issues that will be further discussed in this text.

\section{Mixed Economy of Welfare and Marketization of Social Services - to- wards New Public Management}

Political and economic circumstances in Europe necessitate a proper mixed, shared contribution in the delivery of social services by all sectors (informal, voluntary, state, for-profit), within the so-called "mixed economy of welfare". In most of the European countries, this trend is triggered predominantly by the need to reduce the financial contributions of the state (residualism) (Munday, 2003). With the entry of the private for-profit sector in the delivery of social services, social services are increasingly being used by citizens in need who are not necessarily poor and marginalized (e.g. families with older or disabled people in need of support through social services for full-time, day or temporary care - hospice, respite, or any other services they can afford).

The responsibility for service provision, that is to say, if services should be provided by the state or by the private market, has been discussed in Europe in recent years. The tendency towards service provision by nonpublic entities was promoted by the "New Management Approach" that emerged under the Thatcher and Reagan governments in the 1980s in the UK and in the US. It argues for a more effective and efficient service and benefits provision in a market where increased competition should ensure lower costs. This market of private providers (both for-profit and not for-profit) can be stimulated by the state by contracting or enabling service users to buy services with vouchers or cash payments. Moreover, the approach argues for fewer input controls and a stronger focus on performance and impact. Under the "New Public Management" approach, service users are considered as customers and civil servants as service managers, applying the case management approach in providing access to required services for the user. "New Public Management" has also affected the universal model of welfare provision in Scandinavian countries. For example, the "Act on Free Choice Systems" in Sweden was introduced in 2009 in order to encourage municipalities to implement voucher models that support service user's choice and higher competition between service providers (European Social Network, 2016). In England and Sweden, criteria for accessing care for older people were amended to focus on those most in need and on home care, and this led to an increase in non-public service providers (Brennan, et al., 2012).

The "New Public Management" approach has been criticized with the arguments that private sector methods, such as the aim to increase produc- 
tivity, can have a negative impact on working conditions and service quality, while Brennan and collaborators (2012) stress a threat for class based segregation due to limited access to private services. Ranci and Pavolini (2015) point out that application of this method in Sweden led to standardization of tasks and to a larger number of service users per care worker.

Yet, despite the critiques, the marketization trend prevails and gets stronger, partially because it goes along with solid advocacy for service users' choice.

\section{Social Services Users and Families - Caregivers in the Focus}

\subsection{Increased User-involvement, Participation and Choice}

There is a strong trend in Europe towards involving users at different levels in the process of provision of social services, although with noticeable differences between countries. Due to growth of consumerism and an increased questioning of the unchallenged expertise of professionals, social protection systems have been criticized for their unwillingness to take sufficient account of the needs and wishes of service users. As a consequence, traditional "We know best" approach in providing social services is being replaced by an approach that is more open to user involvement. Replacement of the traditional paternalistic social work practices and bureaucratic authoritarianism (especially in the countries of Central and Eastern Europe) is being justified with the right of the user to a personal choice. There is less secrecy in the operation of agencies and a more democratic style of service provision is adopted by professional staff (e.g. users' rights to have access to their case files). The rights of service users are better defined (e.g. agencies must have published complaints systems). Increased attention is paid to service standards, performance indicators and formal mechanisms for control and inspection. A specific development in changing to a user orientation is the introduction of "client budgets" or "direct payments" systems. Namely, money is paid directly to the service user in cash or in a form of voucher to enable him/her to purchase services that he/she chooses (e.g. this is a feature of the German long-term care insurance scheme for older people).

Although this is a general trend for all developed countries in Europe, progress is uneven, with Nordic countries taking a lead. The Netherlands in particular gives high priority in social services to client orientation, with a shift in attention towards the needs of clients, available information services and setting up users' consultancy groups within social service facilities, which may also include relatives and carers (Munday, 2003). User involvement is also provided for through presence of users during work interviews of potential care workers, or through organization of meetings between the user and the job applicant (EASPD, 2013). Likewise, there are practical examples of established multi-professional teams with service users being 
members of these teams that work with adults with mental health problems or learning difficulties (Montero, 2016).

Promotion of the choice for service users contrasts with the traditionnal approach to welfare, as it empowers service users to decide which services they wish to use. For example, associations of people with disabilities in England, Sweden and Denmark have played a major role in advocating for more freedom of choice and flexibility (Brennan, et al., 2012). In long-term care, a number of states introduced reforms based on direct payments to service users, such as the APA - "Personal Allowance for Autonomy" in France and the "Act on the Promotion of Personal Autonomy and Care for Dependent Persons" (also called "Dependency Act") in Spain (European Social Network, 2013). In Poland, there are discussions on whether to implement a system of choice, also in order to enhance formal care and boost the care market (European Social Network, 2016).

\subsection{Support to the informal family care through social services}

Under the influence of demographic trends, family capacities for informal care have weakened. Under these pressures, accompanied by governmental inclinations to shrink social protection expenditures, numerous measures are being introduced (cash benefits and social services) to support informal care provided by the family. Diminishing family capacities to care for older and frail family members are putting the question of balanced responsibility between the family and the state, back on the agenda. Yet, there is a general consent that informal family care should be supported by formal integrated social services provided by the state, not only for the purpose of advancing user care, but also for the purpose of protection of health and wellbeing of carers (Борнарова, 2009).

Different approaches are utilized in European states to strengthen this family role, sometimes through legal provisions intervening in family relations. According to Swane (2001), there is no legal obligation for children to care for their older parents in Scandinavian countries where it is considered that the ideal policy for care of dependent family members is the one in which formal care complements informal care where necessary, and not vice versa. In some other countries (France, Germany, Italy) relatives are obliged to participate in services for home and residential care, depending on their material conditions.

There are variations between European countries in terms of the degree in which formal care complements informal care. For example, families in Finland, France and England mostly use formal care as a support to the informal care. In Italy and Portugal, private care is mostly used to support informal care. In France, social services provided by the private sector are used only to complement public services provided by the state (Lowenstein, 2007). 
Yet, in many European countries, long-term care needs of citizens are only partly met through public services, while care responsibility also lays with users and their families. Because of this, many countries from Continental, South and Central-Eastern Europe are putting back the focus on provision of family care within their long-term care policies (Ranci, Pavolini, 2015). A comparative study (Rostgaard, 2002) found that most of the European countries researched, understood the invaluable contribution of carers to society, to the processes of decreasing the dependency on residential care (without informal care many care recipients would face institutionalization), as well as the need to ease the burden of care work, especially through provision of respite care services as they enable informal carers to take a break from caring responsibilities, but also continue their work while receiving recognition for it.

\section{Professionalization of Social Services}

\subsection{Licensing of social services providers}

Licensing of social services providers is a common practice in all developed European countries, with variations only in terms of whether it is carried out through standard licensing (issuing a work permit that is renewed) or through registration in established systems (registries) of service providers, upon fulfilment of required criteria. Without exception, licensing of social services providers is under jurisdiction of the national, regional or local authorities, namely, the state, which regulates the process, establishes quality criteria to be attained by service providers, and performs monitoring and control over their functioning.

As to the licensing of professionals employed in social services sectors in European countries, considerable differences are evident. Essentially, two licensing forms are present: a) Certification - through which the use of one's professional title (e.g. social worker) is limited only to those professionals with specific knowledge and skills. Certification is a weaker and not so comprehensive form of regulation, which basically only defines who has the right to use a professional title. It neither limits the practice, nor determines which activities are permitted or not; b) Licensing - is a specific procedure within which a competent designated body (e.g. chamber, regulatory organ) stipulates specific requirements and limits the practice only to those professionals who satisfy the requirements. Licensing is more restrictive than certification, as it regulates who can practice a certain profession through setting up criteria for education, work experience, administration of qualification exams, conditions for license renewal and withdrawal, explicitly, the right to practice a profession.

Analysis of conditions in this domain in a wider European context, reveals several principal tendencies that are in the focus of public debates 
and policies, which will be elaborated further in this text. The tendencies are related to the visible specialization of social services staff for work with specific social services users, as well as to the need for increased work force professionalization typical of social services sector, in particular within the subfield of personal care services.

\subsection{Specialization and work force diversity in the social services sector}

Key professional staff engaged in social services sector are social workers, but also others having diverse professional titles in different countries: social assistant, animator, residential care worker etc. In some countries (i.e. Spain) local agencies for social services employ staff from related professions such as psychologists and sociologists. Unpaid volunteers also make substantial contributions to the social services delivery in many countries (Munday, 2003).

Diversity of care professionals within the social services sector and their specialization, often obtained through specialized courses within the vocational education systems or direct on-the-job training, is visible through the following examples of specialized staff: social service professionals, elderly care professionals, practical nurse, home support worker, disability support worker in Finland; handicap and home helpers, social and health service aids, social and health service assistants, day care workers in Denmark; care worker for older people, professional care worker, health and care assistant in Germany; social assistant worker, social health worker, family assistant in Italy and many others.

In all EU countries, social workers have national professional associations advocating their interests and establishing codes of practice for the profession. In social care, workers' representation is inevitably less developed given the diversity of jobs in this area and the lack of regulation in many countries (European Social Network, 2017).

\subsection{Professionalization of the work force within social care services}

Demographic challenges create specific conditions in the developed European countries. Namely, social services are being increasingly designed and delivered as social care services, especially for older, frail and disabled people. The demand for this type of social care services has boosted, while the supply has not always responded to the demands. Simultaneously, there is a considerable shortage of qualified work force attracted to this labour market sector, as it is considered to be labour intensive. Consequently, there are no high and strict criteria related to professional qualifications of workers in the sector, such as licensing, or even registration (for example, in Poland, until 2001, no formal qualifications were required to obtain work in home care services, residential homes or with disabled people (European Union, 2006)), 
part of the workers obtain minimum qualifications through short-term training, all in order to meet the demands for care work force that is often mobile and exits the care services sector shortly after employment, due to limited opportunities for career upgrading on the work place (European Union, 2006). As Jacobs (2013) points out, there is an acute shortage of workers in this sector in most of the European countries. Cancedda (2001) refers to the UK example, emphasizing that in the UK, labour shortages in the home care sector stem from the difficulty in recruiting personnel who are willing to work in household services. Such unwillingness is the result of the occupation's low salaries and poor working conditions, as well as the improved prospects for finding alternative work in the labour market. Coomans (2002) anticipates that the labour force shortages in this sector that demands low qualified workers, will step up also in the future, especially if the trend of improved educational status of the population is taken into consideration.

The current situation solicits numerous debates and endeavours for professionalization of the work force in social care services, as an inevitable goal aimed at providing quality in the delivery of services to the users and obtaining required competencies by the workers to be able to respond to the demands of the work place characterized by professional stress and burnout. Due to frequent engagement of immigrant workers in this sector, special emphasis is put on the needs for language training, training about the local culture of care, as well as cultural sensitivity training. Also, since this is a sector in which women as traditional carers dominate, the importance of involvement of men and youth during recruitment of workers, is also emphasized. Moreover, the need for registration of workers for the purposes of facilitated access to relevant training and developing a feeling of professional identity, is pointed out (European Social Network, 2016a). Registering the social care workforce is an effective first step in professionalizing social care and gives public authorities and/or regulators contact with an often "hidden" workforce. Registration can be connected to advice on workers' rights and available training courses. In the long run, this can improve working conditions with the potential to reduce turnover, and improve the quality of care provided. To this end exactly, Northern Ireland has been performing registration of all workers in the care services sector (European Social Network, 2017).

Basically, in Europe as a "knowledge-based society", a cross-European tendency exists to upgrade formal qualification standards in the care sector, but at the same time, due to shortages of workers, qualification standards are not situated high on the agenda, while entrance of insufficiently educated, so-called "experienced carers", is still allowed in the sector (Matthies, 2011). There is also an evidence of sometimes contradictory policies and tendencies of parallel increasing and decreasing of qualification standards. Constant upgrading of qualifications of the already working staff as 
well as making the training for social carers attractive for young people (even as a BA-degree of social carers and social instructors at the universities of applied sciences at the level 6), carried out in Finland in 2010, is an example on this. At the same time, a new one-year short-term training was introduced for adult social carers and for migrants as care assistants in order to supply the high quantitative demand of staff in social services (Super, 2010).

While there is still a declarative intention to advance these standards, due to labour market demands in this sector, trends of "dequalification" of professional standards and "flexibilization" of labour market regulations, is used widely in care services. These tendencies are often justified with the neo-liberal labour market policy according to which each unemployed individual should be "activated" in any kind of job, so the social services sector is often seen as solution for labour market placement (Matthies, 2011).

\section{Conclusion}

Social services differ from one country to another, mainly as they are being conditioned and designed according to specificities of country's historical development, socio-economic situation, as well as prevailing social problems and needs of citizens.

Social services sectors within social protection systems throughout Europe have undergone an intensive enlargement in the last several years. Demographic changes, especially observable amid changes of the population age structure and dropping fertility rates below the level required for population reproduction, largely influence the direction in which social services have been developing. These developments impose the necessity for meeting social protection needs of citizens through social services. In fact, this is a key driver of the growing demand for quality social services. Moreover, the role of social services is all the more crucial as they not only represent a source of employment generation, but are also a strategic tool for strengthening social cohesion and active inclusion.

Furthermore, the need for protection of service users by means of setting up minimum standards of services, improved competences of professionals in this sector, as well as increased trust in professionals by service users and increased user-involvement and participation, is ever more important.

Relative to the professionalization of this sector, it may be concluded that while for social workers engaged in social services sector there is clear definition of qualification standards (usually graduate or postgraduate studies), there is huge diversity regarding other professional profiles in terms of required qualifications, with a mixture of staff who are not formally qualified or staff trained on the job. 


\section{References}

Brennan, D., Cass, B., Himmelweit, S., Szebehely, M. (2012). The marketization of care: Rationales and consequences in Nordic and liberal care regimes. Journal of European Social Policy. 22:4.

Борнарова, С. (2009). Соцзијалната политика и старите хицุа. Скопје: Фииозофски факултет.

Cancedda, A. (2001). Employment in household services. European foundation for the Improvement of living and working conditions. Luxembourg.

Coomans G. (2002). Labour supply in a European context: Demographic determinants and competence issues. Paper presented at the conference "Care workers: Matching supply and demand", Sheffield Hallam University.

EASPD (2013). Tool kit on recruitment and retention in social services sector. The European association of service providers for persons with disabilities.

European Union (2006). Employment in social care in Europe. European foundation for the improvement of living and working conditions. Dublin. Ireland.

European Social Network (2013). Independent living: making choice and control a reality. European Commission. Brussels.

European Social Network (2016). Integrated social services in Europe: A study looking at how local public services are working together to improve people's lives. European Commission. Brussels.

European Social Network (2016a). Annual review 2016. European Commission. Brussels.

European Social Network (2017). Investing in the social services workforce. European Commission. Brussels.

Jacobs, S. et al. (2013). The personalization of care services and the early impact on staff activity patterns. Jounral of social work. 13:2.

Kautto, M. (2002). Investing in services in West European welfare states. Journal of European Social Policy. Vol 12:1.

Lowenstein, A. (2007). Intergenerational solidarity: Strengthening Economic and Social Ties. Background Paper. UN Department of Economic and Social Affairs.

Matthies, A. L. (2011). Social service professions: Towards cross-european standardization of qualifications. Social Work and Society. International online journal. Vol. 9. No 1.

Montero, L., et al. (2016). Integrated social services in Europe. European social network. 
Munday, B. (2003). European social services: A map of characteristics and trends. Council of Europe.

Ranci, C., Pavolini, E. (2015). Not all that glitters is gold: Long-term care reforms in the last two decades in Europe. Journal of European Social Policy. Vol. 25:3.

Rostgaard, T. (2002). Caring for children and older people in Europe - A comparison of European policies and practice. Policy Studies. Vol. 23. No. 1.

Swane, E. C. (2001). The relationship between informal and formal care. Keio Journal of Medicine. No. 47.

Super (2010). Practical nurse training. The finish union of practical nurses. 